\title{
KURIKULUM PROGRAM STUDI PENDIDIKAN PANCASILA DAN KEWARGANEGARAAN BERBASIS DIGITAL DI ERA REVOLUSI INDUSTRI 4.0
}

\author{
${ }^{1}$ Yogi Nugraha, ${ }^{2}$ Sapriya, ${ }^{3}$ Endang Danial, ${ }^{4}$ Rahmat \\ ${ }^{1}$ Universitas Buana Perjuangan Karawang \\ ${ }_{2,3,4}$ Universitas Pendidikan Indonesia \\ 1'yogi.nugraha@ubpkarawang.ac.id*; ${ }^{2}$ sapriya@upi.edu; ${ }^{3}$ endangdanial@upi.edu; ${ }^{4}$ rahmat@upi.edu
}

\begin{abstract}
ABSTRAK
Kurikulum Program Studi Pendidikan Pancasila dan Kewarganegaraan secara nasional belum dapat menemukan titik temu dalam kurikulum intinya. Akan tetapi memang didalam perkembangan zaman tuntutan dalam pengembangan kurikulum harus terus dilakukan. Perkembangan zaman yang dimaksudkan adalah perkembangan revolusi industri 4.0 yang berkaitan dengan penggunaan teknologi digital. Tujuan penelitian ini secara umum adalah untuk mengetahui kurikulum Program Studi Pendidikan Pancasila dan Kewarganegaraan berbasis digital di Indonesia menghadapi era revolusi industri 4.0. Metode yang digunakan dalam penelitian ini adalah studi pustaka atau disebut juga studi teks. Studi pustaka digunakan untuk memahami secara mendalam dan komprehensif tentang kurikulum Program Studi Pendidikan Pancasila dan Kewarganegaraan di era revolusi industri 4.0. Hasil yang diperoleh menunjukkan bahwa kurikulum Program Studi Pendidikan Pancasila dan Kewarganegaraan identik dengan muatan hak dan kewajiban warga negara, demokrasi, hak asasi manusia, nasionalisme, geopolitik, dan geostrategik. Kurikulum Program Studi Pendidikan Pancasila dan Kewarganegaraan perlu untuk memperbaharui sistem pembelajaran serta model pembelajaran mengikuti perkembangan zaman. Secara praktis hasil penelitian ini dapat digunakan sebagai bahan referensi penulisan penelitian PPKn lebih lanjut. Kemudian hasil penelitian ini dapat dijadikan bahan kajian mengenai kurikulum prgram studi PPKn dalam menghadapi era revolusi industri 4.0.
\end{abstract}

Kata kunci: Kurikulum, Pendidikan pancasila dan Kewarganegaraan, Revolusi Industri 4.0

\section{ABSTRACT}

The curriculum of the Pancasila and Citizenship Education Study Program is digital-based in the era of the industrial revolution 4.0. The national curriculum for the Pancasila and Citizenship Education Study Program has not yet been able to find common ground in the core curriculum. However, in the current development, the demands in curriculum development must be continued. The development of the times that is meant is the development of the 4.0 industrial revolution related to the use of digital technology. The purpose of this study in general is to determine the digital-based curriculum of the Pancasila and Citizenship Education Study Program in Indonesia facing the era of the industrial revolution 4.0. The method used in this research is literature study or also called text study. Literature study is used to understand in depth and comprehensively about the curriculum of the Pancasila and Citizenship Education Study Program in the era of the industrial revolution 4.0. The results obtained indicate that the curriculum of the Pancasila and Citizenship Education Study Program is identical to the content of the rights and obligations of citizens, democracy, human rights, nationalism, geopolitics, and geostrategic. The curriculum of the Pancasila and Citizenship Education Study Program needs 
to renew the learning system and learning models to keep up with the times. Practically the results of this study can be used as reference material for further PPKn research writing. Then the results of this study can be used as study material regarding the PPKn study program curriculum in the face of the industrial revolution era 4.0. and geostrategic. The curriculum of the Pancasila and Citizenship Education Study Program needs to renew the learning system and learning models to keep up with the times. Practically the results of this study can be used as reference material for further PPKn research writing. Then the results of this study can be used as study material regarding the PPKn study program curriculum in the face of the industrial revolution era 4.0. and geostrategic. The curriculum of the Pancasila and Citizenship Education Study Program needs to renew the learning system and learning models to keep up with the times. Practically the results of this study can be used as reference material for further $P P K n$ research writing. Then the results of this study can be used as study material regarding the PPKn study program curriculum in the face of the era of the industrial revolution 4.0. Keywords: Curriculum, Pancasila and Citizenship Education, industrial revolution 4.0

\section{PENDAHULUAN}

Kemajuan teknologi informasi di dunia menjadi sebuah keniscayaan ditengah kebutuhan manusia akan teknologi itu sendiri. Tidaklah mungkin pada saat ini seseorang dapat menghindar dari terpaan teknologi yang kian hari kian masuk kedalam sendi-sendi kehidupan umat manusia. Dunia dapat dikatakan telah berubah seiring dengan bertambahnya umur bumi dan umur peradaban manusia. Kemajuan dunia yang diikuti kemajuan teknologi telah dapat terprediksi sejak saat teknologi mesin uap saat era revolusi industri 1.0. Pada saat itu diprediksi bahwa peranan manusia dalam pekerjaan sehari-hari akan tergantikan oleh teknologi yang akan semakin berkembang. Seperti pernyataan yang menyatakan bahwa Civilization is meant to be the totality of material works issued by people and this defines its stage of development being the particular type of society making it different from the others. Hal ini berarti bahwa peradaban merupakan sebuah peninggalan yang dihasilkan oleh masyarakat dalam bentuk yang berbeda beda (Fraticiu, 2015). Hal ini berarti pula setiap peradaban menimbulkan perubahan dalam setiap waktunya. Begitupun dengan kurikulum sebagai sebuah media untuk menyiapkan seseorang dalam beradaptasi dengan perubahan. Artikel ini menjelaskan tentang bagaimana seharusnya kurikulum Program Studi Pendidikan Pancasila menerapkan digitalisasi dalam proses pembelajarannya.

Perubahan dunia mengharuskan kita untuk dapat menyesuaikan perilaku kita dengan perubahan tersebut. Pernyataan “... who can consistently perpetuate, timely develop the ideals and values of democracy, and effectively deal with and manage constantly emerging crises for the betterment of Indonesian society as an integral part of a peaceful and welfare global society" dimaksudkan kepada masyarakat yang cerdas dan baik adalah mereka yang secara 
ajek memelihara, dan mengembangkan cita-cita dan nilai demokrasi sesuai perkembangan jaman, dan secara efektif dan langgeng menangani dan mengelola krisis yang selalu muncul untuk kemaslahatan masyarakat Indonesia sebagai bagian integral dari masyarakat global yang damai dan sejahtera (Winataputra, 2012). Percepatan sistem produksi dalam berbagai hal tidak lepas dalam penggunaan teknologi sebagai pendukungnya. Ketergantungan manusia akan teknologi seakan tidak pernah dapat diputus mata rantainya, bahkan teknologi dapat mempermudah pekerjaan manusia. Populasi manusia di dunia semakin hari semakin bertambah, ini mengartikan bahwa kebutuhan akan suatu barang dan jasa setiap waktu semakin meningkat. Inilah yang menjadi alasan bahwa manusia membutuhkan sesuatu alat yang dapat mempercepat produksi barang. Berkaca pada perkembangan revolusi industri pertama sampai dengan keempat, kita memperoleh pelajaran bahwa ketergantungan manusia akan teknologi bukanlah isapan jempol belaka. Kita merasakan langsung manfaat dari hadirnya teknologi dalam setiap sudut kehidupan kita. Revolusi industri pertama menawarkan teknologi yang meringankan beban manusia. Penggunaan mesin uap dalam produksi memangkas waktu dan tenaga yang dibuang manusia. Langkah ini disebut sebagai penemuan teknologi yang mutakhir. Proses produksi dilakukan dengan lebih cepat ketimbang pada saat seluruhnya menggunakan tenaga manusia. Keterbatasan yang ada pada manusia berindikasi pada lambatnya proses produksi barang yang dilakukan sehingga kebutuhan dengan ketersediaan barang tidak sesuai dengan seharusnya.

Pernyataan tersebut sejalan dengan pernyataan yang menyatakan bahwa "University as higher education institution creating young generation of national leader has very strategic role in the process ofyoung generation's character building" (Komalasari, 2012). Saat ini kurikulum Program Studi Pendidikan Pancasila dan Kewarganegaraan sudah seharusnya mulai berbenah dan menyesuaikan kurikulum sesuai dengan arah kemajuan jaman. Kurikulum yang ada saat ini masih belum mampu menjawab tantangan jaman dan belum mampu menghasilkan lulusan yang setara antar sesama program studi yang sama. Sistem pembelajaran yang sudah dilaksanakan agar menyesuaikan kembali dengan dimulainya digitalisasi pendidikan. Era revolusi industri 4.0 atau dikenal juga dengan era disrupsi mengenalkan kepada kita bahwa segala sesuatu dapat dilakukan oleh komputer. Komputerisasi dan penggunaan internet atau pula ada istilah kecerdasan buatan atau artificial intelligence hampir secara keseluruhan menggantikan fungsi manusia sebagai pekerja. Manusia dapat lebih dimanusiakan dalam pekerjaan di luar proses produksi yang telah digantikan oleh teknologi. Permasalahan kurikulum pendidikan kewarganegaraan salah satunya adalah secara mayoritas Program Studi 
Pendidikan Pancasila dan Kewarganegaraan di Indonesia kurikulumnya belum secara keseluruhan memberdayakan teknologi sebagai alat penunjang proses pembelajaran. Hanya sebagian saja yang sudah menerapkan teknologi digital dalam proses pembelajaran, itupun terbatas pada kemampuan atau Sumber Daya Manusia (SDM) dosennya. Fasilitas yang dapat digunakan oleh dosen dalam menggunakan pembelajaran teknologi digital sudah mulai tersedia banyak. Diantaranya Coursera (https://www.coursera.org/), EdX (https://www.edx.org/), Udacity (https://www.udacity.com/), Khan Academy (https://www.khanacademy.org/), Udemy (https://www.udemy.com/), Alison (https://alison.com/), Edmodo (https://www.edmodo.com/), Quipper Video (https://video.quipper.com/id), Zenius (https://www.zenius.net/), google classroom (https://classroom.google.com), dan web ELearning yang dipersiapkan oleh perguruan tinggi secara tersendiri untuk menunjang proses pembelajaran digital.

Berdasarkan sumber daya yang dimiliki oleh masing-masing perguruan tinggi sudah seharusnya kurikulum program studi PPKn disetarakan kemampuan lulusannya dan mampu menjawab tantangan jaman. Pekerjaan yang dapat dilakukan adalah dengan proses peninjauan kurikulum yang dilakukan oleh program studi dengan mendengarkan pendapat pakar, praktisi dan asosiasi serta forum program studi. Sehingga hasilnya nanti dapat disepakati berapa jumlah matakuliah inti dan matakuliah pengembangan atau kekhasan masing-masing program studi. Tentu saja kegiatan tidak berhenti disana, selanjutnya adalah melakukan adaptasi dengan polapola pembelajaran menggunakan teknologi seperti e-learning. E-Learning adalah pemanfaatan berbagai sumber daya yang ada berbentuk teknologi untuk menciptakan pengalaman belajar. E-Learning adalah pendekatan yang inovatif untuk dijadikan sebuah desain media penyampaian yang baik, terpusat pada pengguna, interaktif dan sebagai lingkungan belajar yang memiliki berbagai kemudahan-kemudahan bagi siapa saja, dimana saja dan kapan saja. Dengan memanfaatkan berbagai atribut dan sumber teknologi digital dengan bentuk lain dari materi dan bahan pembelajaran yang sesuai untuk diterapkan pada suatu lingkungan belajar yang terbuka, fleksibel dan terdistribusi (Horton, 2003).

\section{METODE PENELITIAN}

Metode penulisan ini adalah metode studi pustaka. Studi pustaka atau disebut juga studi teks Noeng Muhadjir Penelitian ini adalah penelitian studi teks atau studi pustaka. Studi teks menurut Noeng Muhadjir (2000:297) mencakup: pertama, telaah teoritik suatu disiplin ilmu yang perlu dilanjutkan secara empirik untuk memperoleh kebenaran secara empirik pula. 
Kedua, studi yang berupaya mempelajari seluruh obyek penelitian secara filosofis atau teoritik dan terkait dengan validitas. Ketiga, studi yang berupaya mempelajari teoritik linguistic. Keempat, adalah studi karya sastra. Salah satu alasan menggunakan metode ini adalah untuk memahami secara mendalam dan komprehensif tentang kurikulum pendidikan kewarganegaraan di era revolusi industri 4.0.

\section{HASIL PENELITIAN DAN PEMBAHASAN}

\section{Hasil Penelitian}

Bagian ini menyajikan hasil penelitian. Hasil penelitian dapat dilengkapi dengan tabel, grafik (gambar), bagan atau deskriptif. Tabel dituliskan di tengah atau di akhir setiap teks deskripsi hasil/perolehan penelitian. Judul Tabel ditulis dari kiri, semua kata diawali huruf besar, kecuali kata sambung. Kalau lebih dari satu baris dituliskan dalam spasi tunggal (at least 12). Sebagai contoh, dapat dilihat Tabel 1 . berikut.

Kurikulum yang dikembangkan oleh pendidikan tinggi atau dalam hal ini program studi sebagai ujung tombaknya dituntut untuk dapat merekonstruksi kembali kurikulum menyesuaikan pedoman terbaru yang sudah ada. Bukan mengganti secara keseluruhan, akan tetapi penyesuaian kurikulum dapat menjadikan lulusan program studi mampu bersaing dengan lulusan perguruan tinggi lain. Selain itu, manfaat yang dapat dirasakan adalah mahasiswa mampu mempercepat proses pekerjaannya dengan menggunakan bantuan teknologi digital. Terdapat 5 (lima) variabel komposit yang harus menjadi perhatian dalam penyusunan sebuah kurikulum pendidikan tinggi mengacu pada revolusi industri 4.0. Kelima variabel tersebut diantaranya adalah Big Data, Internet of Things (IoT), Cloud Computing, Artificial Intelligence, Augmented Reality (Ellahi, 2019).

Revolusi industri 4.0 sendiri merupakan pengembangan daripada revolusi industri sebelumnya. Tujuan daripada revolusi industri 4.0 ini bukan hanya terletak pada meningkatkan produktifitas pada abad ke 21 tetapi juga meningkatkan fleksibilitas dan kemampuan adaptasi. Pada era ini peran internet dan digitalisasi masuk ke segala bidang kehidupan manusia. Proses tersebut dapat juga dikatakan sebagai era disrupsi atau dikenal juga dengan disrupsi teknologi dalam kehidupan manusia. Era disrupsi artinya masuknya peran-peran teknologi yang secara tidak disadari telah mengubah gaya hidup kita. Peran teknologi dan digitalisasi juga berpengaruh terhadap perubahan cara, media dan kebiasaan orang terutama warganegara muda dalam menjalankan kehidupan sehari-hari (Machfiroh et al., 2018). Peran kurikulum dalam era ini adalah menyeimbangkan dan memberikan dasar landasan serta mengintegrasikan antara 
kemampuan mahasiswa dengan kecepatan laju teknologi (Promyoo \& Shashank, 2019). Senada dengan pendapat Promyoo, bahwa penggunaan teknologi adalah untuk membuat seseorang menjadi melek informasi, dan memiliki kemampuan untuk menemukan, mengevaluasi dan menggunakan informasi secara efektif (Spitzer et al., 1998).

Program studi PPKn merupakan salah satu dari banyak program studi di Indonesia sebagai ujung tombak pelaksaan proses pembelajaran dalam dunia pendidikan tinggi. Sebagai sebuah program studi, tentu saja program studi PPKn menjalankan kegiatan proses pembelajaran sesuai dengan aturan yang telah dibuat melalui standar nasional pendidikan tinggi (SNPT) yang diatur dalam Peraturan Menteri Riset, Teknologi, dan Pendidikan Tinggi republik Indonesia Nomor 44 Tahun 2015 tentang Standar Nasional Pendidikan Tinggi. Selain itu beberapa dasar hukum dalam pengembangan kurikulum di program studi PPKn adalah:

1. UU No. 20 tahun 2003 tentang Sistem Pendidikan Nasional

2. UU No. 12 tahun 2012 tentang Pendidikan Tinggi

3. Perpres No. 8 tahun 2012 tentang KKNI

4. Permenristekdikti No. 32 tahun 2016 tentang Akreditasi Program Studi dan Perguruan Tinggi

Selain daripada itu, program studi mengacu kepada kesepakatan asosiasi yang mewadahi keilmuan program studi. Pada program studi PPKn, asosiasi tersebut bernama Asosiasi Profesi Pendidikan Pancasila dan Kewarganegaraan Indonesia (AP3KnI). Pernyataan kurikulum mengacu pada definisi istilah kurikulum yang ada pada Pasal 35 UU No. 12 Tahun 2012 tentang Pendidikan Tinggi ayat (1) yang menyebutkan bawa kurikulum pendidikan tinggi merupakan seperangkat rencana dan pengaturan mengenai tujuan, isi, dan bahan ajar serta cara yang digunakan sebagai pedoman penyelenggaraan kegiatan pembelajaran untuk mencapai tujuan Pendidikan Tinggi. Pernyataan tersebut diperkuat dengan ayat (2) yang menyatakan bahwa Kurikulum Pendidikan Tinggi sebagaimana dimaksud pada ayat (1) dikembangkan oleh setiap Perguruan Tinggi dengan mengacu pada Standar Nasional Pendidikan Tinggi untuk setiap Program Studi yang mencakup pengembangan kecerdasan intelektual, akhlak mulia, dan keterampilan. Pernyatan pada ayat (2) menyiratkan bahwa kurikulum yang disusun oleh perguruan tinggi harus mengacu pada SNPT yang terdiri dari 24 (dua puluh empat) standar. Menurut Pasal 1 ayat (6) Permenristekdikti No. 44 Tahun 2015 tentang SNPT menyebutkan bahwa kurikulum adalah seperangkat rencana dan pengaturan mengenai capaian pembelajaran lulusan, bahan kajian, proses, dan penilaian yang digunakan sebagai pedoman penyelenggaraan program studi. Penyusunan kurikulum yang berorientasi pada teknologi informasi tentu akan 
sangat membuka peluang bagi informasi-informasi yang ada diseluruh dunia masuk. Masuknya pengaruh global tentu akan sangat mempengaruhi bagi terbentuknya tujuan PKn yang telah dijelaskan di atas. Usaha-usaha untuk membuat metode-metode belajar PKn agar lebih menarik dalam kurikulum PKn sebetulnya memang pernah dilakukan. Salah satu upaya yang telah dilaksanakan adalah membuat Civicpedia untuk membantu proses pembelajaran siswa SMA di sekolah menggunakan teknologi digital (Abdulkarim et al., 2019). Namun demikian, usahausaha untuk terus membuat kurikulum PKn dan Prodi PPKn harus selalu terus diupayakan menyesuaikan dengan perkembangan zaman.

Proses perbaikan atau revisi kurikulum Program Studi PPKn disesuaikan dengan tipe pembelajaran abad 21 yang mengedepankan 4C yang meliputi Communication, Collaboration, Critical Thinking, Creative and Innovative sangat perlu dilakukan guna mengembangkan kemampuan calon guru PPKn dalam menyongsong masa depannya. Jika kita cermati dan teliti, pada abad ke-21 ini kebutuhan akan hasil akhir dalam sebuah pendidikan bukanlah manusiamanusia yang hanya bisa membaca, menulis dan berhitung. Jauh dari itu kebutuhan akan hasil akhir sebuah proses pendidikan adalah manusia-manusia yang mampu berkomunikasi, mampu berkolaborasi, mampu berpikir kritis dan manusia yang mempunyai kreativitas. Kebutuhan akan kurikulum yang mampu mempersiapkan lulusan program studi PPKn yang siap pakai diperlukan dalam menjawab tantangan dunia yang semakin mengglobal dan ketersediaan sumber daya yang ada di dunia. Pernyataan tersebut mengartikan bahwa sumberdaya yang tersedia saat ini di dunia membutuhkan pengelolaan bersama yang akhirnya harus dikolaborasikan dan disiapkan dalam bentuk pendidikan.

\section{Pembahasan}

Proses pembelajaran abad 21 digolongkan kedalam 3 kategori besar yaitu keterampilan informasi dan komunikasi, keterampilan pemikiran dan pemecahan masalah, dan keterampilan interpersonal dan self directional (Sahin, 2009)

Tabel 1 Kategori Pembelajaran Abad 21

\begin{tabular}{ccccc}
\hline $\begin{array}{c}\text { Keterampilan informasi } \\
\text { dan komunikasi }\end{array}$ & $\begin{array}{l}\text { Keterampilan pemikiran } \\
\text { dan pemecahan masalah }\end{array}$ & $\begin{array}{c}\text { Keterampilan } \\
\text { interpersonal dan self } \\
\text { directional }\end{array}$ \\
\hline $\begin{array}{l}\text { Keterampilan dan } \\
\text { literasi data }\end{array}$ & $\begin{array}{l}\text { Berpikir kritis dan } \\
\text { system }\end{array}$ & $\bullet$ Self-arah \\
\hline
\end{tabular}


E ISSN : 2580-5517

\begin{tabular}{llll}
\hline $\begin{array}{l}\text { Kemampuan } \\
\text { komunikasi }\end{array}$ & $\begin{array}{l}\text { Identifikasi masalah, } \\
\text { formulasi dan solusi } \\
\text { Kreativitas dan rasa } \\
\text { ingin tahu intelektual }\end{array}$ & $\begin{array}{l}\text { Akuntabilitas dan } \\
\text { kemampuan } \\
\text { beradaptasi } \\
\end{array}$ & $\begin{array}{l}\text { Tanggung jawab } \\
\text { sosial:tanggung } \\
\text { jawab sosial }\end{array}$ \\
\hline
\end{tabular}

Berdasarkan pendapat Sahin di atas, peran keterampilan informasi dan literasi media yang merupakan penjabaran dari perlunya teknologi sebagai pendukung proses pembelajaran membuktikan bahwa teknologi memang begitu penting dan memang diperlukan dalam membangun sebuah proses pembelajaran. Hal ini didukung oleh pernyataan yang menyebutkan bahwa sepanjang sejarah manusia, pendidikan dibentuk oleh kebutuhan manusia dan sudah diatur untuk itu (Sahin, 2009). Karena kebutuhan akan teknologi dirasa sangat penting bagi manusia maka proses pendidikan di setiap tingkatnya diarahkan menuju peningkatan berpikir kritis dan melek teknologi. Hal ini diperkuat dengan pernyataan bahwa dimasa depan, penggunaan internet akan terus tumbuh lebih tinggi karena produksi ponsel perangkat yang telah melampaui 2 miliar dan diperkirakan akan melampaui 2,7 miliar (Hanchman, 2011). Penjabaran proses pembelajaran abad 21 (Partnership for 21 st Century Skills 2008) dapat dijabarkan dalam poin-poin berikut:

1. Tekankan pelajaran inti.

2. Tekankan keterampilan belajar.

3. Gunakan alat untuk mengembangkan keterampilan belajar abad ke-21.

4. Ajarkan dan belajar konteks abad 21

5. Ajarkan dan belajar konten abad 21

6. Gunakan penilaian abad ke-21 yang mengukur keterampilan abad 21

Berkembangnya teknologi dan pola-pola pembelajaran menuntut pesertanya untuk dapat beradaptasi dengan perkembangan jaman dan mampu menyongsong era baru dalam dunia pendidikan. Sebagai sebuah institusi yang mempersiapkan calon pendidik sebagai profil lulusannya, program studi PPKn harus mengembangkan sebuah kurikulum belajar yang sesuai dengan perkembangan proses belajar di abad 21. Pembelajaran abad 21 erat kaitannya dengan perkembangan dunia teknologi dalam proses pembelajaran. Permasalahannya adalah pada jaman ini semua pihak yang terlibat dalam dunia pendidikan haruslah mampu mengikuti dan bahkan menguasai teknologi dalam dunia pendidikan. Teknologi tidak lagi dipandang sebagai sebuah alat produksi dan juga tidak lagi hanya identik dengan dunia industry. Akan tetapi, 
teknologi sudah merambah pada semua sendi kehidupan manusia tidak terkecuali dalam dunia pendidikan.

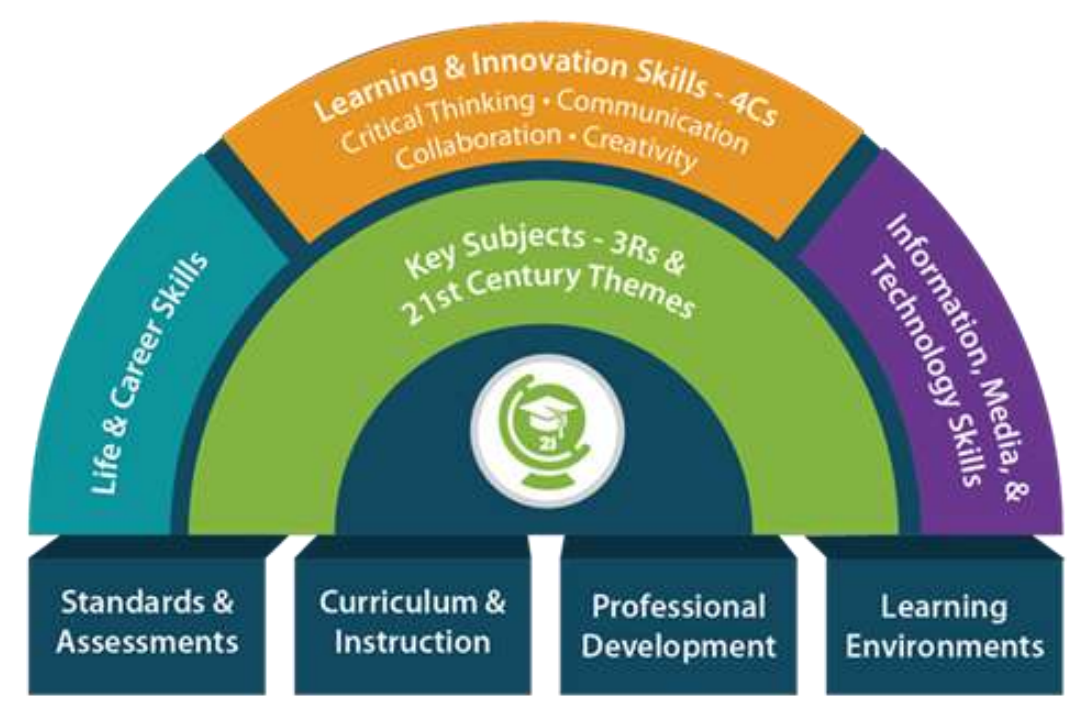

Gambar 1 Konsep Pembelajaran Abad 21

Melihat konsep yang digambarkan di atas sangatlah jelas bahwasannya peran guru sangatlah penting dalam mempersiapkan kehidupan dan skill yang nantinya dimiliki oleh peserta didiknya. Guru harus mampu mengakselerasi kemampuan peserta didiknya melalui skill yang dimiliki. Guru harus mampu menguasai proses pembelajaran melalui berbagai inovasi dan skill peserta didik melalui proses berpikir kritis, komunikasi, kolaborasi dan kreativitas yang dimiliki. Serta guru harus mampu menguasai informasi, media dan kemampuan menguasai teknologi khususnya teknologi dalam proses pembelajaran.

Tantangan Guru Pada Abad 21 yaitu ada empat sifat yang muncul di abad 21 yang mempengaruhi kehidupan dan peradaban manusia (Surakhmad, 2018), yaitu:

1. Bahwa akan terjadi perubahan yang besar di dalam hampir semua bidang kehidupan, dan bahwa perubahan tersebut akan berlangsung semakin hari semakin terakselerasi.

2. Bahwa peranan ilmu pengetahuan dan teknologi akan mengambil posisi yang sentral yang langsung mempengaruhi bukan saja gaya hidup manusia sehari-hari, tetapi juga mempengaruhi nilai-nilai seni, moral dan agama. 
3. Bahwa pertarungan dan persaingan hidup antara bangsa-bangsa tidak akan terbatas di bidang ekonomi saja, tetapi juga di berbagai bidang lainnya, termasuk bidang budaya dan ideologi.

4. Bahwa karena pengaruh ilmu dan teknologi, nilai-nilai moral dan agama akan langsung tercabut dan bukan mustahil akan menimbulkan sistem nilai yang berbeda dari apa yang dikenal sampai saat ini. Seiring dengan sentralnya peranan Iptek, perkembangan industri berbasis iptek akan berkembang dengan cepat.

Berdasarkan pendapat tersebut, dapat diartikan bahwa pembelajaran abad 21 sangat berkaitan dengan era revolusi industry 4.0 yang menuntut semua pihak yang berkepentingan dalam dunia pendidikan untuk dapat beradaptasi terhadap perkembangan jaman. Sehingga dengan menguasai teknologi kita perlu juga mewaspadai pengaruh-pengaruh buruk yang ditimbulkan oleh perkembangan jaman tersebut.

Perlunya kemampuan skill yang dimiliki warganegara dalam konteks PKn disebut dengan Civic Skills. Kompetensi esensial kedua dari civic education (Pendidikan Kewarganegaraan) dalam masyarakat demokratis adalah keterampilan atau kecakapankecakapan kewarganegaraan (civic skills). Jika warga negara mempratikkan hak-haknya dan menunaikan kewajiban-kewajibannya sebagai anggota masyarakat yang berdaulat, mereka tidak hanya perlu menguasai pengetahuan dasar sebagaimana diwujudkan dalam lima pertanyaan sebagaimana diuraikan di muka, namun mereka perlu memiliki kecakapankecakapan intelektual dan parsipatoris yang relevan (Branson, 1998). Kecakapan-kecakapan intelektual kewarganegaraan sekalipun dapat dibedakan namun satu sama lain tidak dapat dipisahkan dari kontennya. Kecakapan berpikir kritis tentang isu politik tertentu.

Kecakapan-kecakapan intelektual yang penting untuk seorang warga negara yang berpengetahuan, efektif, dan bertanggung jawab, disebut sebagai kemampuan berpikir kritis. Kecakapan intelektual itu meliputi kemampuan mengidentifikasi, menggambarkan, menjelaskan, menganalisis, menilai, mengambil, dan mempertahankan posisi atas suatu isu (Branson, 1998). Keterampilan kewarganegaraan disebutkan meliputi keterampilan berpartisipasi dalam kehidupan berbangsa dan bernegara, berperan serta aktif mewujudkan masyarakat madani (civil society), keterampilan memengaruhi dan memonitoring jalannya pemerintahan dan proses pengambilan keputusan politik, keterampilan memecahkan masalah sosial, keterampilan mengadakan koalisi, kerjasama, dan mengelola konflik.

Sementara itu juga, keterampilan kewarganegaraan (civic skills), merupakan keterampilan yang dikembangkan dari pengetahuan kewarganegaraan, agar pengetahuan yang 
diperoleh menjadi sesuatu yang bermakna, karena dapat dimanfaatkan dalam menghadapi masalah-masalah kehidupan berbangsa dan bernegara (Setiawan, 2014). Civic skills mencakup intellectual skills (keterampilan intelektual) dan participation skills (keterampilan partisipasi). Keterampilan intelektual yang terpenting bagi terbentuknya warga negara yang berwawasan luas, efektif dan bertanggung jawab antara lain adalah keterampilan berpikir kritis. Keterampilan berpikir kritis meliputi: mengidentifikasi, menggambarkan/mendeskripsikan, menjelaskan, menganalisis, mengevaluasi, menentukan dan mempertahankan pendapat yang berkenaan dengan masalah-masalah publik.

Dalam konteks penelitian ini, civic skills atau keterampilan warganegara mengarahkan perhatiannya pada bagaimana mahasiswa sebagai calon seorang guru dapat memiliki kemampuan teknologi khususunya teknologi IT yang mampu mempermudah dalam proses pembelajaran dan mampu berinovasi dalam mengembangkan konten-konten pembelajaran sesuai dengan pembelajaran abad 21 dan kemajuan di era rrevolusi industry 4.0.

Pentingnya keterampilan bahwa As society changes over time, more skills need to be acquired in order to prepare for a better future (Osman \& Marimuthu, 2010). Pendapat tersebut mengartikan bahwa perubahan yang terjadi di dunia ini dari waktu ke waktu, membuat manusia sangat membutuhkan keterampilan dalam rangka mempersiapkan masa depan yang lebih baik. Masa depan yang dimaksud adalah masa depan yang dipersiapkan dengan keterampilan manusia didalamnya. Digitalisasi berbagai aspek kehidupan membuat kurikulum yang diselenggarakan oleh Program Studi PPKn haruslah berorientasi pada proses keterampilan penggunaan teknologi khususnya teknologi digital.

\section{Kesimpulan}

Permasalahan yang muncul dalam arus teknologi dan digitalisasi adalah sikap konvensional yang menutup diri dari pengaruh teknologi yang masuk. Padahal, kita tidaklah mungkin dapat membendung masuknya pengaruh teknologi. Jika kita memperhatikan apa yang telah terjadi pada awal abad ke 20 ketika Henry Ford membutuhkan waktu sekitar 20 tahun untuk memasarkan 15 juta unit mobil padahal saat ini produsen smartphone berhasil memasarkan 1,5 milyar smartphone tersebut hanya dalam waktu satu tahun yaitu pada tahun 2015. Mesin pencarian seperti google dan Wikipedia sebagai pusat informasi telah berhasil menumbangkan encyclopedia Britannica yang telah berjalan selama 250 tahun berturut-turut. Kemudian, waktu yang dihabiskan oleh para pengguna internet adalah lebih dari 20 jam per minggu (Anonim, 2016). Menyadari akan hal tersebut, sudah sewajarnya dunia pendidikan 
mulai saat ini dan khususnya pendidikan kewarganegaraan harus menyesuaikan perkembangan tersebut sesuai dengan kemajuan teknologi dan informasi. Bukan berarti menggantikan peran seorang pendidik dalam menyampaikan ilmu pengetahuan kepada mahasiswa dalam konteks perguruan tinggi, akan tetapi caranya lah yang harus mulai menyesuaikan dengan perkembangan jaman. Perkembangan teknologi informasi lantas tidak begitu saja menghilangkan ajaran-ajaran tentang moral dan karakter, tetapi menyiapkan digitalisasi pendidikan juga sangat penting untuk dilaksanakan. Peran perguruan tinggi sangat besar dalam menumbuhkan kemampuan mahasiswa untuk dapat menguasai teknologi. Teknologi yang digunakan dalam pendidikan kewarganegaraan tidak terlepas dari proses pembelajaran yang menggunakan teknologi digital baik itu model pembelajaran maupun penggunaan aplikasi pembelajaran dalam perkuliahan sehari-hari.

\section{DAFTAR PUSTAKA}

Abdulkarim, A., Ratmaningsih, N., \& Anggraini, D. N. (2019). Developing Civicpedia as a Civic Education E-Learning Media To Improve Students' Information Literacy. Journal of Social Studies Education Research, 9(3), 45-61.

Branson. (1998). The Role of Civic Education. CCE.

Ellahi, R. M. (2019). Redesigning Curriculum in line with Industry 4.0. Journal Procedia Computer Science, 151(2019), 699-708.

Fraticiu, L. (2015). Culture-Civilization-Organizational Culture and Managerial Performance. Journal Procedia Economics and Finance, 27, 69-72.

Hanchman, M. (2011). IDC: Mobile Internet Use to Pass PCs by 2015. http://www.pcmag.com/article2/0.2817.2392796.00.asp

Horton, W. (2003). E-Learning Tools and Technologies: A consumer guide for trainers, teachers, educators, and instructional designers. Wiley Publishing, Inc.

Komalasari, K. (2012). The Living Values-Based Contextual Learning to Develop the Students' Character. Journal of Social Sciences, 8(2), 246-251.

Machfiroh, R., Sapriya, S., \& Komalasari, K. (2018). Characteristics of Young Indonesian Citizenship in the Digital Era. https://doi.org/10.2991/acec-18.2018.2

Osman, K., \& Marimuthu, N. (2010). Setting new learning targets for the 21 st century science education in Malaysia. Journal Procedia Social and Behavioral Sciences, 1, 3737-3741.

Promyoo, R., \& Shashank. (2019). Innovative Digital Manufacturing Curriculum for Industry 4.0. Journal Procedia Manufacturing, 34(2019), 1043-1050.

Sahin, M. C. (2009). Instructional design principles for 21 st century learning skills. Journal Procedia 
Yogi Nugraha, Sapriya, Endang Danial, Rahmat

Vol 5 No 1

ISSN : 2541-6995

E ISSN : 2580-5517

Social and Behavioral Sciences, 1, 1464-1468.

Setiawan, D. (2014). Pendidikan Kewarganegaraan Berbasis Karakter melalui Penerapan Pendekatan Pembelajaran Aktif, Kreatif, Efektif dan Menyenangkan. Jurnal Pendidikan Ilmu-Ilmu Sosial, $6(2), 61-72$.

Spitzer, K. ., Eisenberd, M. B., \& Lowe, C. . (1998). Information Literacy: Essential Skill for the Information Age. Clearinghouse on Information \& Technology Syracuse University.

Surakhmad, W. (2018). Konsep dan Prinsip Pokok Pembelajaran Abad 21. https://www.defantri.com/2018/04/konsep-dan-prinsip-pokok-pembelajaran.html

Winataputra, U. (2012). Pendidikan Kewargangaraan Dalam Perspektif Internasional (Konteks, Teori, Dan Profil Pembelajaran). Widya Aksara Press. 